\title{
Environmental magnetic and geochemical characteristics of Chennai coastal sediments, Bay of Bengal, India
}

\author{
R Venkatachalapathy ${ }^{1, *}$, S Veerasingam ${ }^{2}$, N Basavaiah ${ }^{3}$, \\ T RAMKUMAR $^{4}$ and K DEENADAYALAN ${ }^{3}$ \\ ${ }^{1}$ Centre of Advanced Study in Marine Biology, Faculty of Marine Sciences, Annamalai University, \\ Parangipettai 608 502, Tamil Nadu, India. \\ ${ }^{2}$ Department of Physics, Annamalai University, Annamalainagar 608 002, Tamil Nadu, India. \\ ${ }^{3}$ Environmental Magnetism Laboratory, Indian Institute of Geomagnetism, New Panvel, \\ Navi Mumbai 410 218, India. \\ ${ }^{4}$ Department of Earth Sciences, Annamalai University, Annamalainagar 608 002, Tamil Nadu, India. \\ ${ }^{*}$ Corresponding author. e-mail: venkatr5@rediffmail.com
}

In this study, environmental magnetic, heavy metal and statistical analyses were conducted on 21 surface sediments collected from Chennai coast, India, to examine the feasibility of heavy metal pollution using magnetic susceptibility. The Chennai coastal sediment samples are dominated by ferrimagnetic minerals corresponding to magnetite-like minerals. The percentage of frequency dependent magnetic susceptibility reflects the presence of super-paramagnetic/single domain magnetic minerals in Chennai harbour, Cooum and Adayar rivers sediments. High pollution load index in sample E1, E2, CH7, C11, C12 and A16 is mainly due to anthropogenic activities such as, harbour activities, Cooum and Adayar rivers input and industrial effluent. Factor analysis shows that the magnetic concentration dependent parameters $(\chi$, $\chi_{\mathrm{ARM}}$ and SIRM) covary with the heavy metal concentrations, suggesting that the input of magnetic minerals and heavy metals in Chennai coastal sediments are derived from the same anthropogenic sources. Strong correlation obtained between pollution load index (PLI) and concentration dependent parameters $\left(\chi, \chi_{\mathrm{ARM}}\right.$ and SIRM) for the polluted samples with magnetic susceptibility excess of $50 \times 10^{-8} \mathrm{~m}^{3} \mathrm{~kg}^{-1}$. Significant correlations between heavy metals and magnetic susceptibility point out the potential of magnetic screening/monitoring for simple and rapid proxy indicator of heavy metal pollution in marine sediments.

\section{Introduction}

Magnetic particles in coastal sediments are usually derived primarily from terrestrial sources via fluvial and eolian transportation. Since industrialization, however, iron oxides originating from anthropogenic fly-ashes from factories and vehicles may also significantly contribute to the magnetic properties of marine sediments. This is especially common in coastal settings and marginal seas adjacent to heavily populated and industrialized areas (Horng et al 2009). Environmental magnetic or mineral magnetic measurements are being used as a powerful tool for the assessment of heavy metal contamination in sediments and in the investigation of the compositional properties of rocks and sediments (Thompson and Oldfield 1986; Maher and Thompson 1999; Walden et al 1999). Magnetic susceptibility values depend on the composition and grain size of magnetic minerals. Coastal sediments represent

Keywords. Environmental magnetism; heavy metals; pollution load index; marine sediments; multivariate statistical analysis. 
natural sinks of magnetic minerals and heavy metals of different origin, from lithogenic as well as pedogenic and anthropogenic sources.

Many researchers reported that magnetic susceptibility measurements are very useful in investigating industrial discharges and exhaust gasses in urban regions. It appears that atmospheric deposition is one of the major sources of contamination in coastal and marine sediments (Chan et al 1998, 2001; Alagarsamy 2009; Horng et al 2009; Canbay et al 2010). The high magnetic susceptibility observed in marine sediments could result from different mechanisms, such as diagenetic changes in magnetic mineralogy (Karlin et al 1987), fine grained iron oxides derived from anthropogenic sources (Chan et al 2001), an increased input of detrital magnetite from soil erosion (Maher and Taylor 1988; Higgitt et al 1991), high concentration of magnetotactic bacteria in marine sediment (Lovley et al 1987).

Flanders (1994) has suggested that virtually all magnetic particles generated by industrial processes have a diameter $>2 \mu \mathrm{m}$, but Matzka and Maher (1999) suggest that those from vehicular emissions are relatively smaller $(<2.5 \mu \mathrm{m})$. Pedogenic ferrimagnetic minerals are predominantly in superparamagnetic $(<0.02 \mu \mathrm{m})$ to stable single domain
(SSD) $(0.02-0.04 \mu \mathrm{m})$ grain sizes (Maher 1988; Zhou et al 1990), whereas anthropogenic magnetic particles have been suggested to be generally dominated by multi-domain ( $\mathrm{MD}>10 \mu \mathrm{m})$ and $\mathrm{SSD}$ size (Hay et al 1997).

The specific objectives of this study are:

- to determine the magnetic concentration, mineralogy and grain size of magnetic minerals in Chennai coastal sediments,

- to examine the relationship between magnetic properties and heavy metals in sediments along the Chennai coast,

- to further examine the feasibility of heavy metal pollution using magnetic susceptibility in marine environment, and

- to provide a scientific basis for pollution control and further pollution monitoring.

\section{Materials and methods}

\subsection{Study area and sampling}

Chennai is the fourth largest city in India and the capital of the Indian state of Tamil Nadu located on the Coromandel Coast of the Bay of Bengal (figure 1).

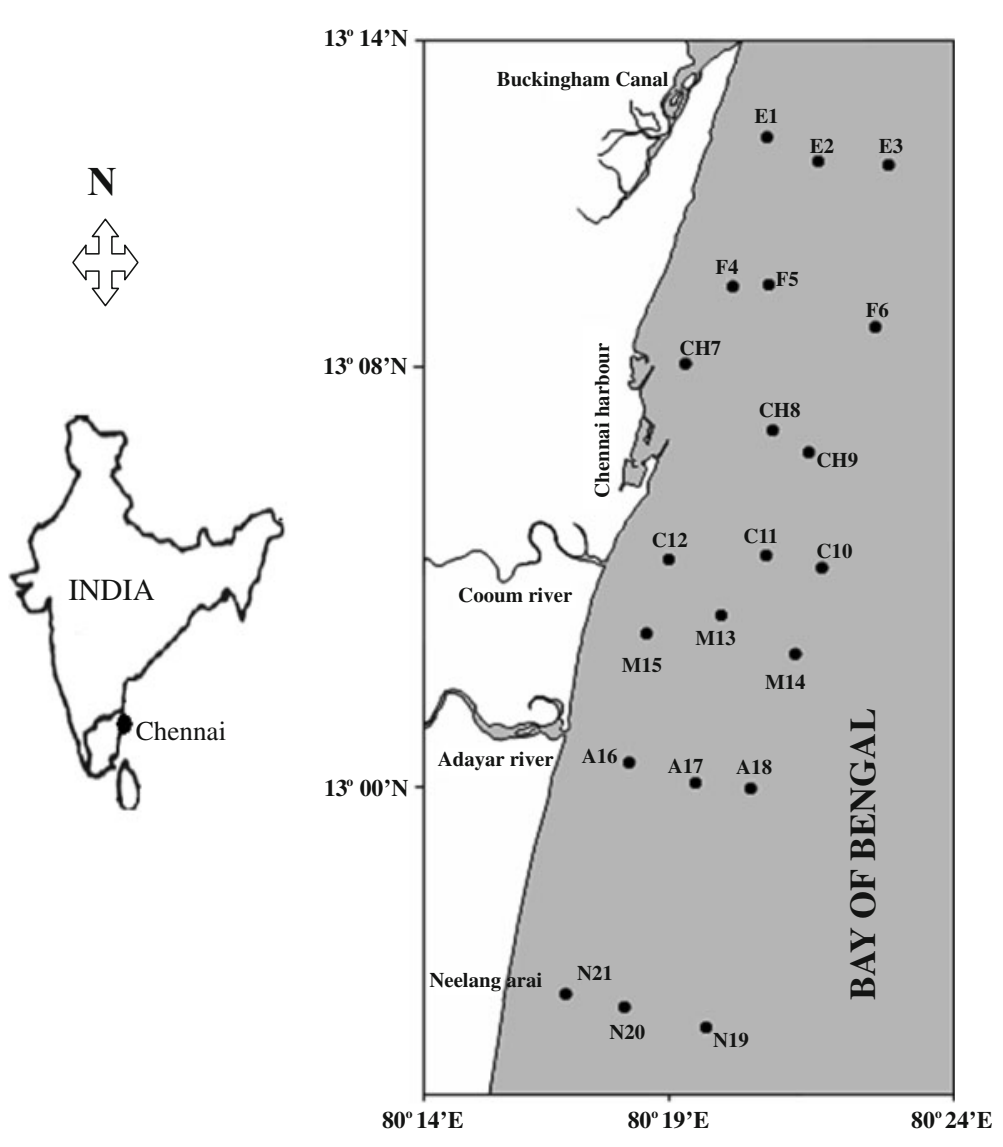

Figure 1. Map of the study area showing the sediment sampling sites in the Chennai coast (E - Ennore; F - Fishing harbour; $\mathrm{CH}$ - Chennai harbour; C - Cooum River; M - Marina; A - Adyar River; N - Neelangarai). 


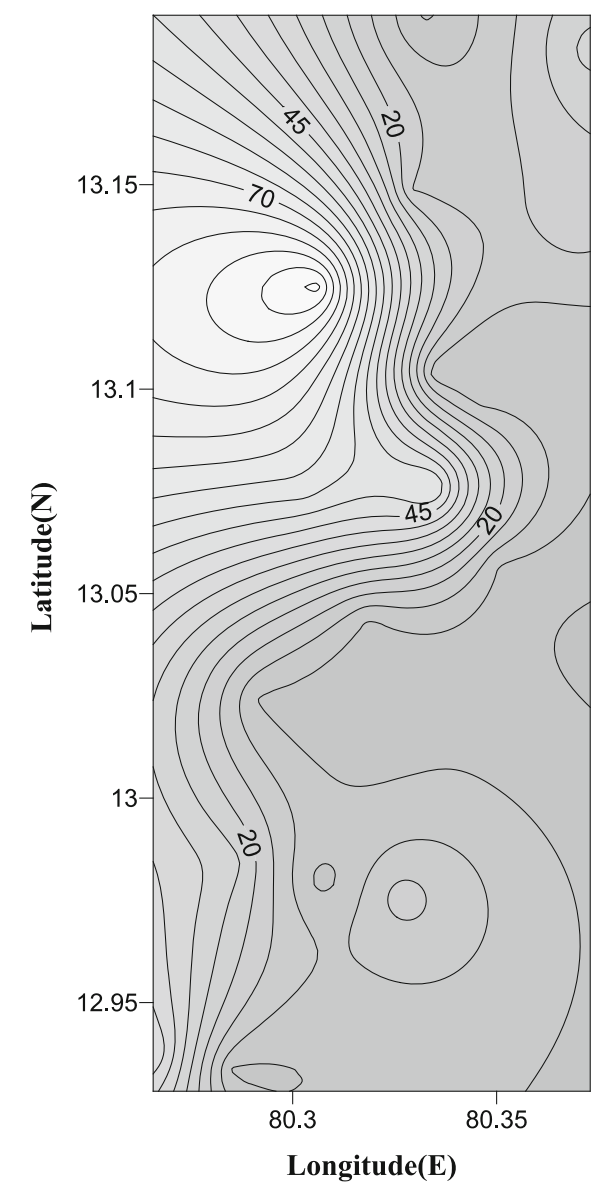

$\chi\left(10^{-8} \mathbf{m}^{3} \mathbf{k g}^{-1}\right)$

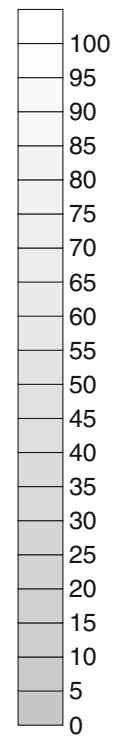

Figure 2. Contour plot of spatial distribution of magnetic susceptibility of the Chennai coastal sediments.

The average wind speed along the Chennai coast is $14.82 \mathrm{~km} / \mathrm{h}$ year round. The deepwater significant wave height varies predominantly between 0.5 and $1 \mathrm{~m}$ during February to April, 1 and $2.5 \mathrm{~m}$ during May to September, and 1 and $2 \mathrm{~m}$ during October to January. Tides in this region are predominantly semi-diurnal, with an average spring tidal range of about $1 \mathrm{~m}$ and an average neap tidal range of about $0.41 \mathrm{~m}$. The average surface and bottom current speed along the Chennai coast is $0.16 \mathrm{~m} / \mathrm{s}$ (Venkatachalapathy et al 2010). Two rivers meander through Chennai, the Cooum River (or Kuvam) through the centre and the Adayar River to the south. The city is served by two major ports, Chennai Port, one of the largest artificial ports, and Ennore Port. Chennai port is the largest port in the Bay of Bengal and is India's second busiest container hub, handling automobiles, motorcycles and general industrial cargo. A smaller harbour at Royapuram is used for harbouring local fishing boats and trawlers.

Twenty-one surface sediment samples were collected from southern Ennore to Neelangarai at 10, 15 and $20 \mathrm{~m}$ water depths in July 2008 during a Cruise onboard the Research Vessel Sagar

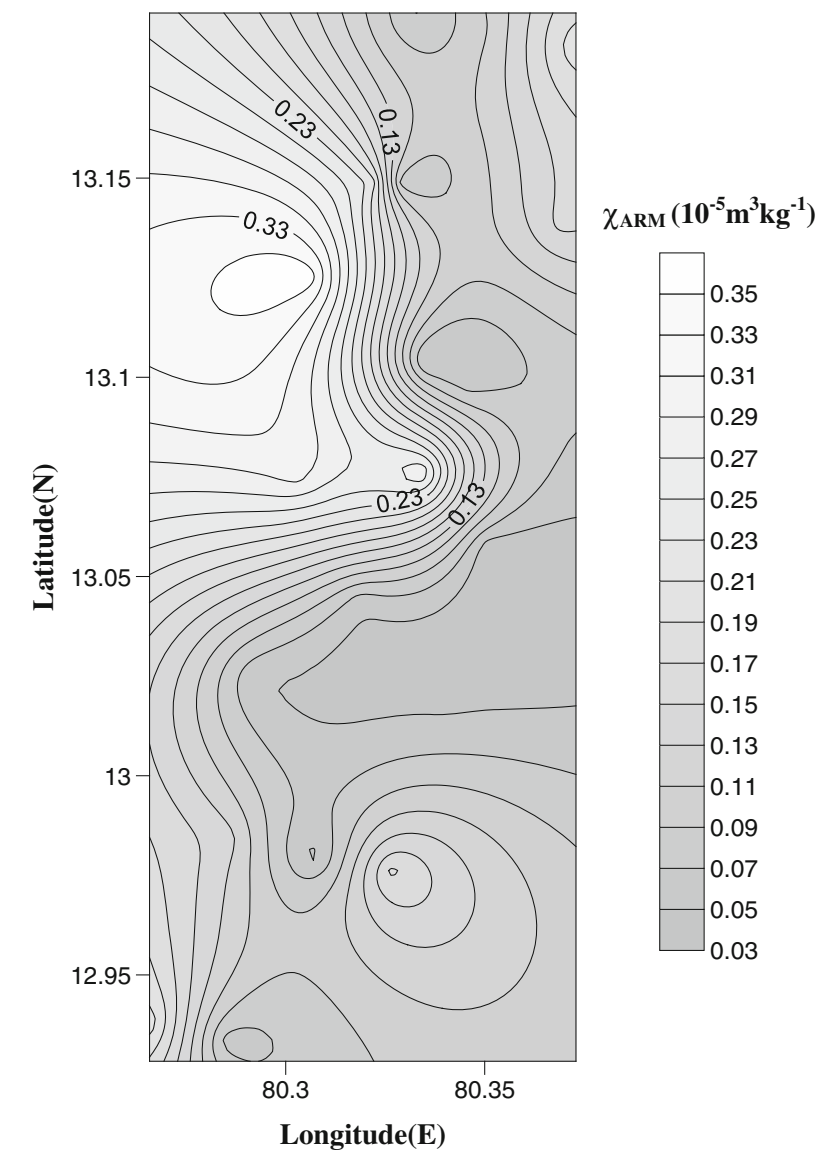

Figure 3. Contour plot of spatial distribution of susceptibility of anhysteric remanent magnetization of the Chennai coastal sediments.

Paschimi, using a Van Veen grab sampler. Differential Global Positioning System (DGPS-Trimble) was used to determine the geo-coordinate points of the sampling locations. The water depth at each sampling point was determined using Multi-beam Echo-sounder. Samples were taken from the central part of the grab sampler to avoid any metallic contamination from the metallic sampler. The samples were packed by self-packing polythene bags and were frozen at $-4^{\circ} \mathrm{C}$ immediately until further analysis.

\subsection{Analytical methods}

\subsubsection{Environmental magnetic analysis}

Magnetic susceptibility measurements were carried out on sub-samples which were dried at $40^{\circ} \mathrm{C}$ and disaggregated. Samples were packed into $10 \mathrm{ml}$ plastic containers, using cling-film to immobilize the sediments. To ensure that the variable sample volumes did not influence results, containers were filled to at least half of their capacity. Magnetic susceptibility measurements were conducted using a magnetic susceptibility meter MS2B with dual 


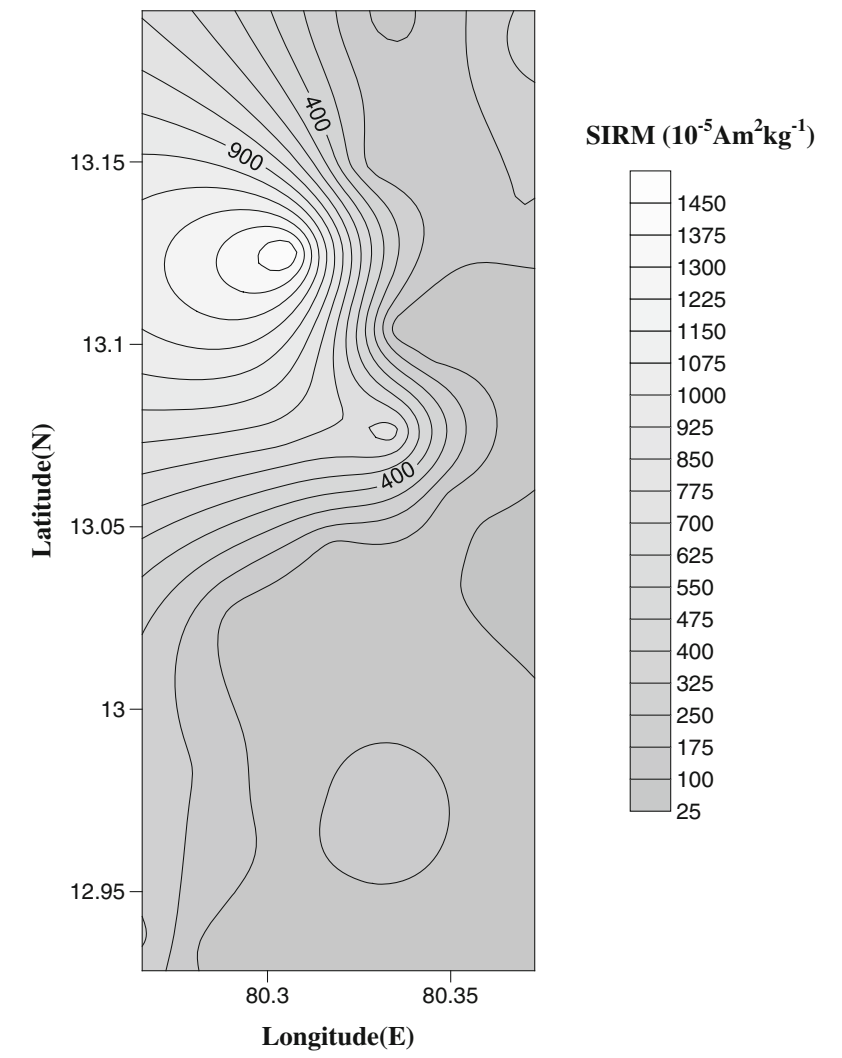

Figure 4. Contour plot of spatial distribution of saturation isothermal remanent magnetization of the Chennai coastal sediments.

frequency sensor $(0.47$ and $4.7 \mathrm{kHz})$. The percentage frequency dependence susceptibility $\chi_{\mathrm{fd}} \%$ is calculated using the following formula:

$$
\chi_{f d} \%=\left(\frac{\left(\chi_{l f}-\chi_{h f}\right)}{\chi_{l f}}\right) \times 100 .
$$

Anhysteric remanent magnetization (ARM), here expressed as susceptibility of ARM $\left(\chi_{\mathrm{ARM}}\right)$, was measured after demagnetization in an AF field of $100 \mathrm{mT}$ inducing a DC biasing field of $0.05 \mathrm{mT}$ using a Molspin AF demagnetizer and Minispin pulse magnetizer, and was measured on the Molspin Minispin magnetometer. Isothermal remanent magnetization (IRM) is the remanent magnetization acquired by a sample after exposure to, and removal from, a steady (DC) magnetic field. IRM depends on the strength of the field applied, which is often denoted by a subscript. It is also a function of the magnetic mineralogy and grain size. IRM was measured for forward fields of $20 \mathrm{mT}, 1 \mathrm{~T}$ and $2 \mathrm{~T}$ and a reverse field of $20,30,40,60,80,100$ and $300 \mathrm{mT} . \mathrm{IRM}_{2 \mathrm{~T}}$ is hereafter, referred to as the saturation isothermal remanent magnetization (SIRM). IRM is often used as an indicator of the presence of ferrimagnetic minerals, but anti-ferromagnetic minerals, such as hematite and goethite also contribute with the excess applied magnetic field of $100 \mathrm{mT}$. SIRM was induced using a Molspin pulse magnetizer. $\chi_{\text {ARM }} /$ SIRM, SIRM/ $\chi$, Soft IRM and Hard IRM were measured using forward DC fields. S-ratio (= - IRM-300/SIRM, being IRM-300 the acquired IRM at a backfield of $300 \mathrm{mT}$ ) were also calculated from IRM measurement, using backfield once the SIRM was reached.

\subsubsection{Geochemical analysis}

Extraction of acid leachable metals was done by taking $0.5 \mathrm{~g}$ of dry sediment sample in a high quality plastic bottle. The samples were mixed with 4:1 ratio $\mathrm{HNO}_{3}: \mathrm{HClO}_{4}$ and allowed to stand overnight. The mixture was then heated to near dryness and allowed to cool before $20 \mathrm{ml}$ of $5 \mathrm{M} \mathrm{HNO}_{3}$ solution was added. The samples were allowed to stand overnight and then filtered through Whatman Grade 'A' filter paper. The filtrates are transferred to a $100 \mathrm{ml}$ volumetric flask and made up to mark with $0.5 \mathrm{M} \mathrm{HNO}_{3}$. Metal concentrations (Fe, $\mathrm{Al}, \mathrm{Mg}, \mathrm{Cu}, \mathrm{Cr}, \mathrm{Ni}, \mathrm{Pb}, \mathrm{Zn}$, and $\mathrm{Mn}$ ) were measured using Inductively Coupled Plasma Optical Emission Spectroscopy (ICP-OES, Perkin-Elmer, Optima 2100 DV). Suitable internal chemical

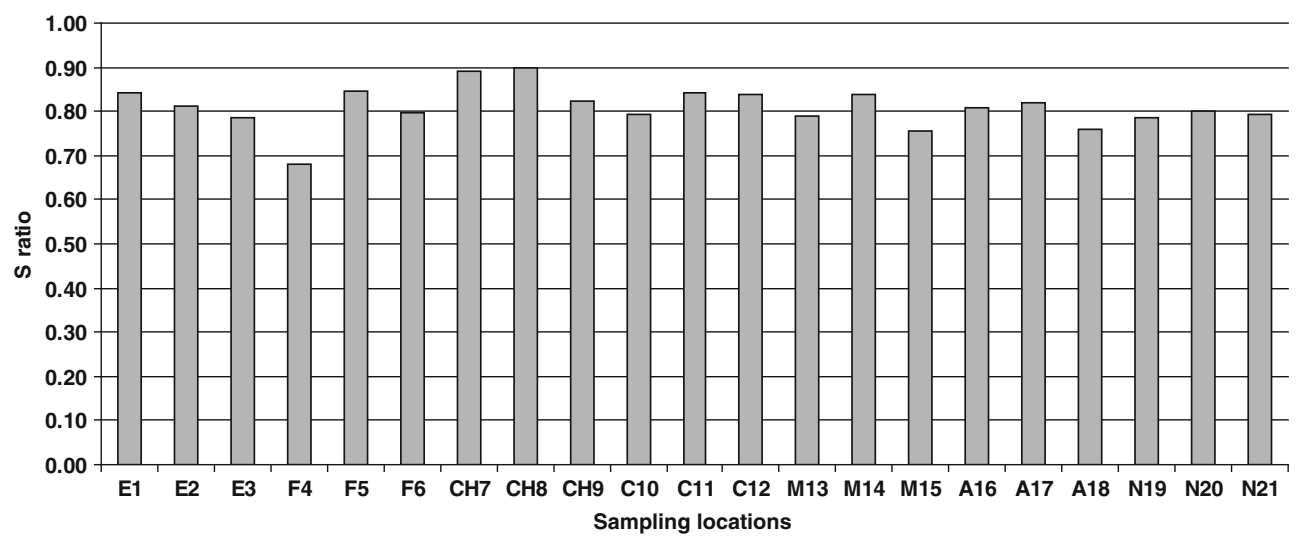

Figure 5. Spatial variation of $\mathrm{S}$ ratio in Chennai coastal sediments. 


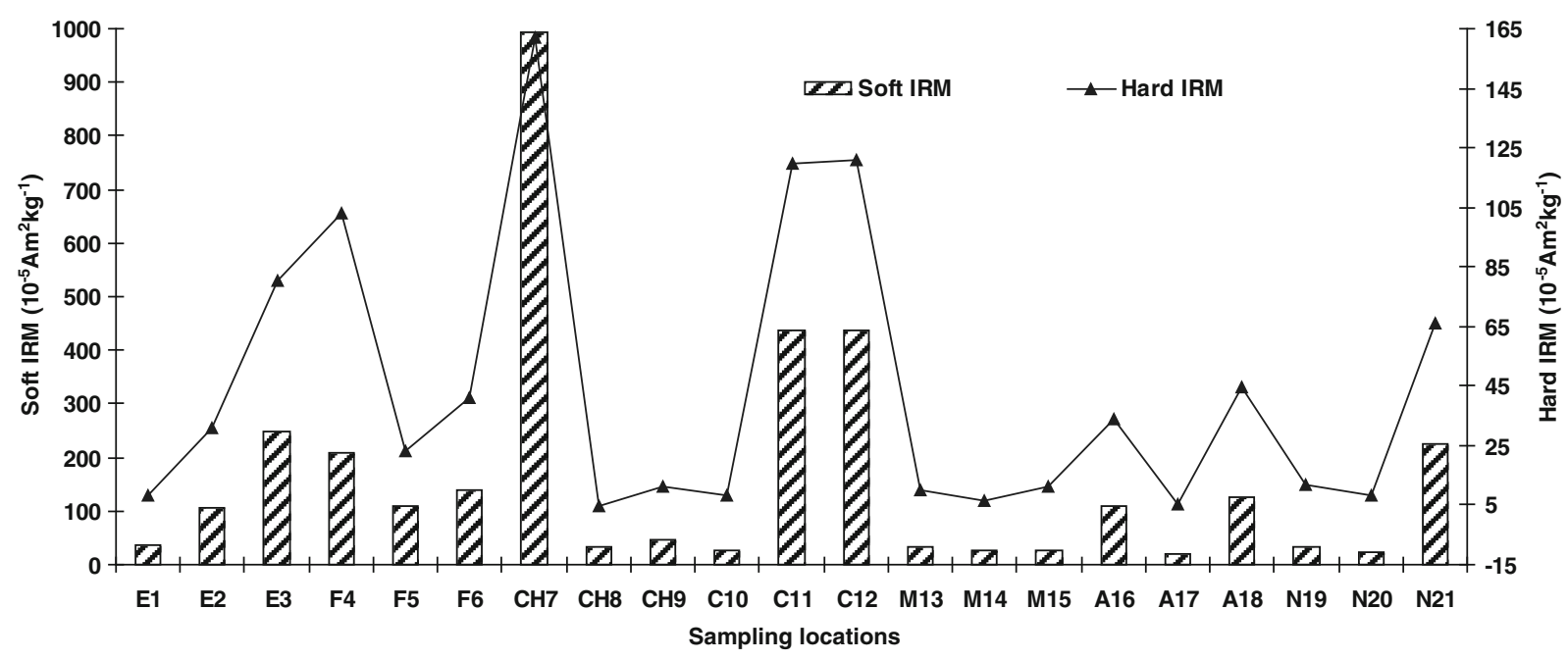

Figure 6. Spatial distribution of soft and hard IRMs in Chennai coastal sediments.

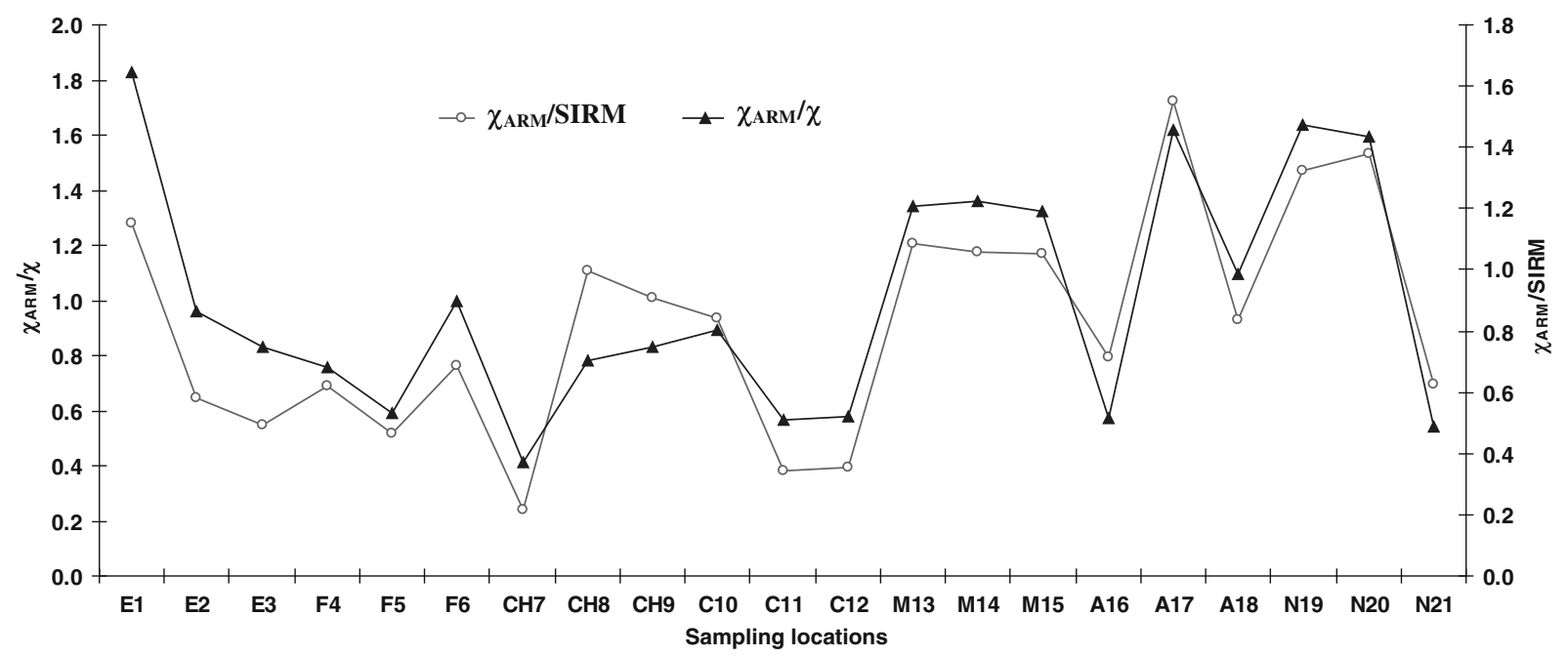

Figure 7. Spatial distributions of magnetic carrier dependent parameter ratios $\left(\chi_{\mathrm{ARM}} / \chi\right.$ and $\left.\chi_{\mathrm{ARM}} / \mathrm{SIRM}\right)$.

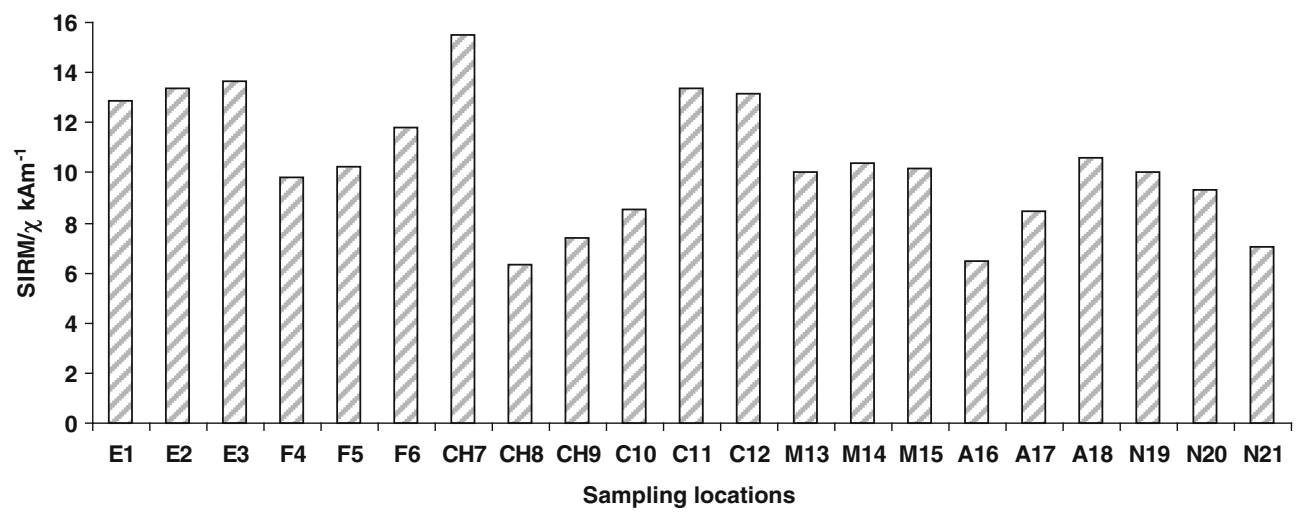

Figure 8. Spatial variation of SIRM/ $\chi$ ratio in Chennai coastal sediments. 
standards (Merck, Germany) were used to calibrate the instrument. Precision and accuracy of the metal analysis were checked against the marine sediment standard reference material from National Institute of Standards and Technology. The analytical precision expressed as coefficients of variance is $<10 \%$ for all the metals, based on replicate analysis.

\subsubsection{Data analysis}

The whole set of data (environmental magnetic and geochemical data) in this study was analysed by multivariate statistical methods, including correlation matrix and varimax rotated factor analysis. All the data processing for statistical analysis was done with the statistical software SPSS for Windows (Ver. 16). Factor analysis was done to identify the relations among the variables and factor scores were computed from correlation matrix rearranged data, so that it explains the relationship between magnetic properties and heavy metals. The factor loadings were based on the eigen values and the factor scores were computed from the original raw data so as to create an entirely new set of smaller composite variables to replace original set of variables and are presented as factor 1 (F1) and factor 2 (F2), respectively.

The Tomlinson pollution load index (PLI) was calculated to examine its correlation with magnetic susceptibility. The linear correlation between the PLI and magnetic susceptibility originally was predicted by Angulo (1996). Chan et al (2001) used the PLI to show how much a sample exceeds the contents of heavy-metal background of the natural environments. A first step in evaluating the impact

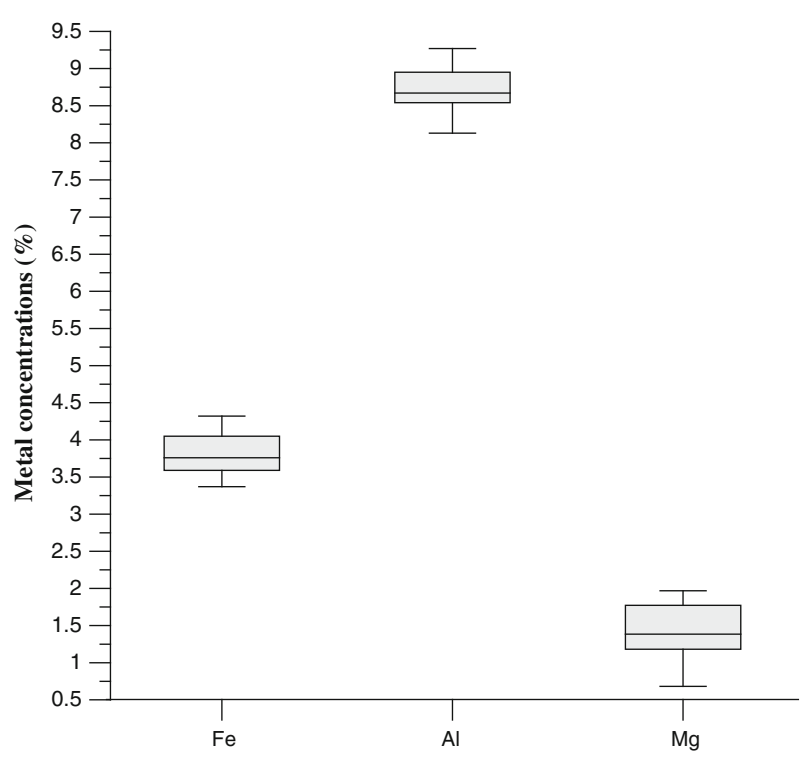

Figure 9. Box-whisker plot of $\mathrm{Fe}, \mathrm{Al}$ and $\mathrm{Mg}$ concentrations in Chennai coastal sediments. of sediment pollution and the level of contamination affecting a given area is to establish a reference background of known metal composition. Three methods are considered, firstly the use of continental crustal values as reference concentrations, and the second method seeks to establish a local baseline by analyzing comparable local sediment unaffected by anthropogenic activity, while the third method is to use the metal content found in deeper sediment (pre-industrial) samples as reference backgrounds (Abrahim and Parker 2008). In this study, continental crustal value (Taylor and McLennan 1995) is considered as background. The PLI which is a result of the contribution of several heavy metals is defined as the root of the multiplication of the concentration factors $\left(C F_{\mathrm{HMK}}\right)$, where $C F_{\text {HMK }}$ was the ratio of the concentrations of each heavy metal $\left(C_{\mathrm{HM}}\right)$ to the background values.

$$
\mathrm{PLI}=\sqrt[n]{\prod_{k=1}^{n} C F_{\mathrm{HMK}}}
$$

where, $C F_{\text {HMK }}$ is the ratio of the concentrations of each heavy metal $\left(C_{\mathrm{HM}}\right)$ to the background values.

$$
C F_{\mathrm{HMK}}=\frac{C_{\mathrm{HM}}}{\text { Background value }} \text {. }
$$

\section{Results and discussion}

\subsection{Magnetic concentration parameters}

Magnetic susceptibility $(\chi)$, susceptibility of anhysteric remanent magnetization $\left(\chi_{\mathrm{ARM}}\right)$ and SIRM are magnetic concentration-dependent parameters.

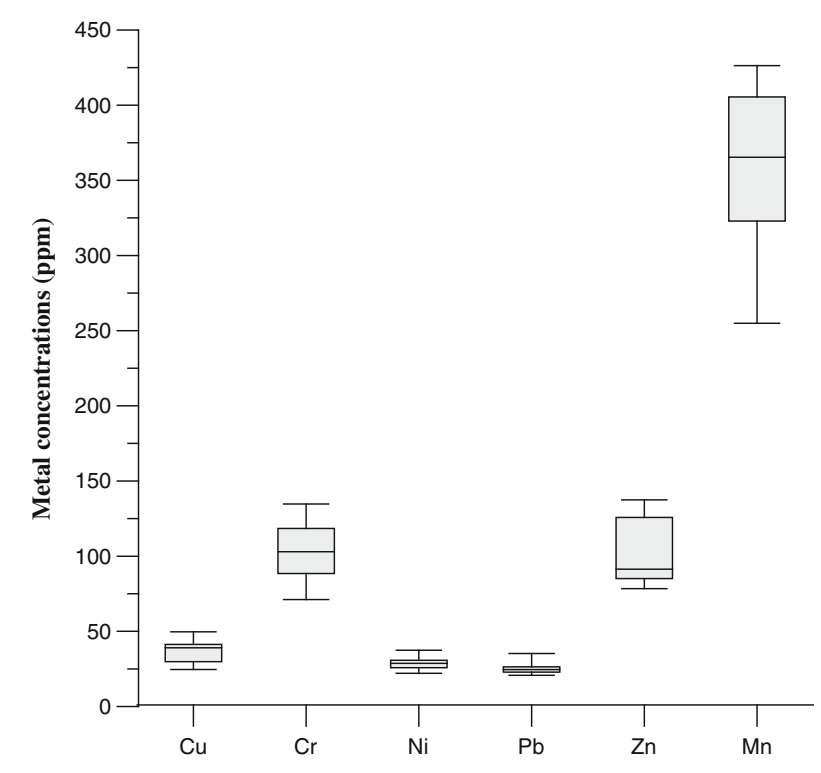

Figure 10. Box-whisker plot of $\mathrm{Cu}, \mathrm{Cr}, \mathrm{Ni}, \mathrm{Pb}, \mathrm{Zn}$ and $\mathrm{Mn}$ concentrations in Chennai coastal sediments. 
Magnetic susceptibility values vary according to the kind of magnetic minerals, i.e., diamagnetic, paramagnetic, anti-ferromagnetic, and ferrimagnetic minerals (Maher et al 1999). The results of $\chi, \chi_{\mathrm{ARM}}$ and SIRM for Chennai coastal sediments are shown in figures 2,3 and 4 , respectively.

The magnetic susceptibility $(\chi)$ of Chennai coastal varied between $3.0 \times 10^{-8} \mathrm{~m}^{3} \mathrm{~kg}^{-1}$ and 96.8 $\times 10^{-8} \mathrm{~m}^{3} \mathrm{~kg}^{-1}$ with an average of $21.72 \times 10^{-8}$ $\mathrm{m}^{3} \mathrm{~kg}^{-1}$. The maximum value of $\chi$ is obtained at Chennai harbour area (CH7) and is $\sim 5$ times higher than the average value $\left(21.72 \times 10^{-8} \mathrm{~m}^{3}\right.$ $\left.\mathrm{kg}^{-1}\right) \cdot \chi_{\mathrm{ARM}}$ values for sediments are in the range of $0.038-0.36 \times 10^{-5} \mathrm{~m}^{3} \mathrm{~kg}^{-1}$ with mean value of $0.134 \times 10^{-5} \mathrm{~m}^{3} \mathrm{~kg}^{-1}$. SIRM of the Chennai sediment samples ranges from 25.41 to $1503.09 \times$ $10^{-5} \mathrm{Am}^{2} \mathrm{~kg}^{-1}$ with an average value of $255.69 \times$ $10^{-5} \mathrm{Am}^{2} \mathrm{~kg}^{-1}$. The observed result from these three parameters $\left(\chi, \chi_{\mathrm{ARM}}\right.$ and SIRM) indicates the presence of ferrimagnetic minerals in Chennai harbour, Cooum and Adayar rivers region.

\subsection{Magnetic mineralogy}

$\mathrm{S}$ ratio, Soft IRM and Hard IRM are magnetic mineralogy dependent parameters. The $\mathrm{S}$ ratio is a dimensionless parameter that indicates content of ferrimagnetic vs. antiferromagentic minerals; values close to 1 correspond to the predominance of ferrimagnetic minerals. Magnetic minerals in sediments can be identified as soft and hard fractions. The soft fraction has low coercivity and is expected to approximate to the concentration of magnetite (Thompson and Oldfield 1986); the hard fraction has high coercivity and can be used to estimate the total concentration of canted antiferromagnetic minerals (hematite) (Oldfield and Richardson 1990). The range of $\mathrm{S}$ ratio for Chennai sediments is $0.68-0.90$ (figure 5) and the Soft IRM and Hard IRM varies from 19.15-994.93 ×
$10^{-5} \mathrm{Am}^{2} \mathrm{~kg}^{-1}$ and $4.46-161.84 \times 10^{-5} \mathrm{Am}^{2} \mathrm{~kg}^{-1}$, respectively (figure 6 ).

Soft IRM is mainly dependent on the concentration of ferrimagnetic minerals. Hard IRM can be used to estimate the total concentration of canted anti-ferromagnetic minerals (hematite). The high values of $\mathrm{S}$ ratio and Soft IRM indicate the presence of ferrimagnetic minerals.

\subsection{Grain size of magnetic minerals}

Frequency dependent susceptibility $\left(\chi_{\mathrm{fd}}\right)$ is an indicator of fine viscous grains near the superparamagnetic (SP) and stable single domain (SSD) boundary, which is around $0.02 \mu \mathrm{m}$ for isodiametric grains and $\chi_{\mathrm{ARM}}$ is used to estimate the contribution of single domain (SD, $\sim 0.03-0.07 \mu \mathrm{m}$ ) ferrimagnetic minerals (Maher 1988). Values of $\chi_{\mathrm{fd}} \%>$ $2.0 \%$ indicates virtually no SP grains; between 2.0 and $10.0 \%$ indicates admixture of SP and coarser non-SP grains; between 10.0 and $14.0 \%$ indicates virtually all SP grains (Dearing 1994). $\chi_{\mathrm{fd}} \%$ is varied from 0.31 to $16.07 \%$ with an average value of $5.26 \%$. The inter-parameter ratios $\chi_{\mathrm{ARM}} / \chi$ and $\chi_{\mathrm{ARM}} / \mathrm{SIRM}$ reflect variations in the ferrimagnetic grain size, with values peaking in the SD range (Maher 1998). The $\chi_{\mathrm{ARM}} / \mathrm{SIRM}$ ratio is related to the magnetic grain size: for magnetite, values greater than about $1 \times 10^{-3} \mathrm{~mA}^{-1}$ are indicative of grains close to stable single domain size (Maher 1998). The inter-parameter ratios $\chi_{\mathrm{ARM}} / \chi$ and $\chi_{\mathrm{ARM}} / \mathrm{SIRM}$ are shown in figure 7 .

The high values of $\chi_{\mathrm{ARM}} / \mathrm{SIRM}$ indicates relatively finer ferrimagnetic grain assemblages and low values of $\chi_{\mathrm{ARM}} / \mathrm{SIRM}$ indicates coarser ferrimagnetic assemblages. The $\mathrm{SIRM} / \chi$ ratio is also a grain size sensitive parameter (figure 8 ).

The values of SIRM/ $\chi$ decrease with increasing grain size for magnetite (Peters and Dekkers 2003). Magnetic grain size parameters $\left(\chi_{\mathrm{fd}} \%, \chi_{\mathrm{ARM}} / \chi\right.$,

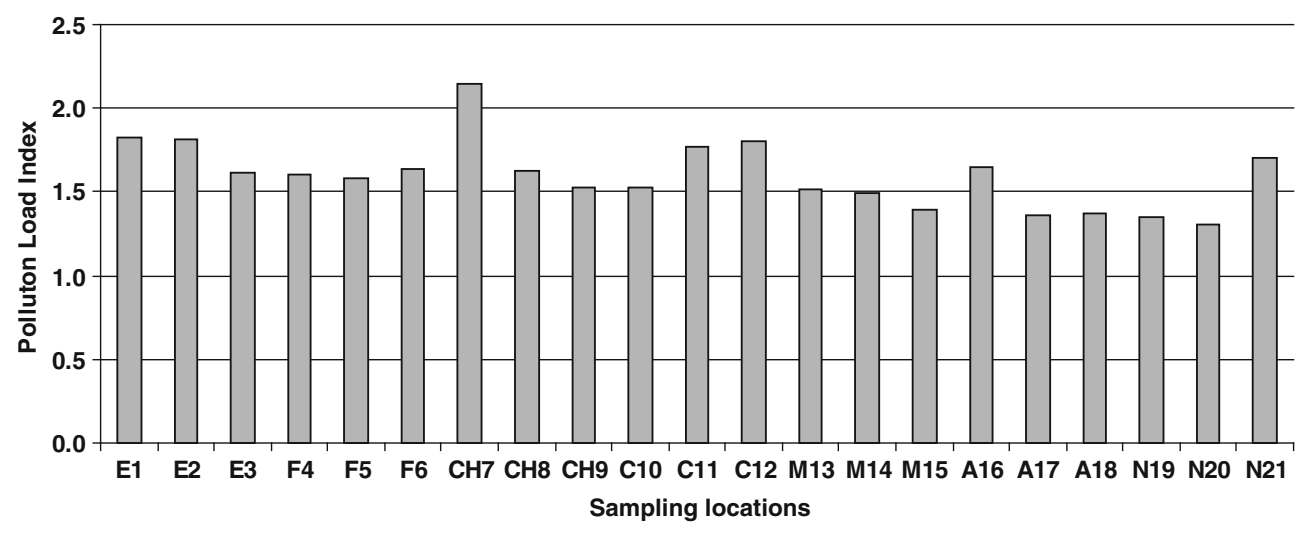

Figure 11. Pollution load index of Chennai coastal sediments. 

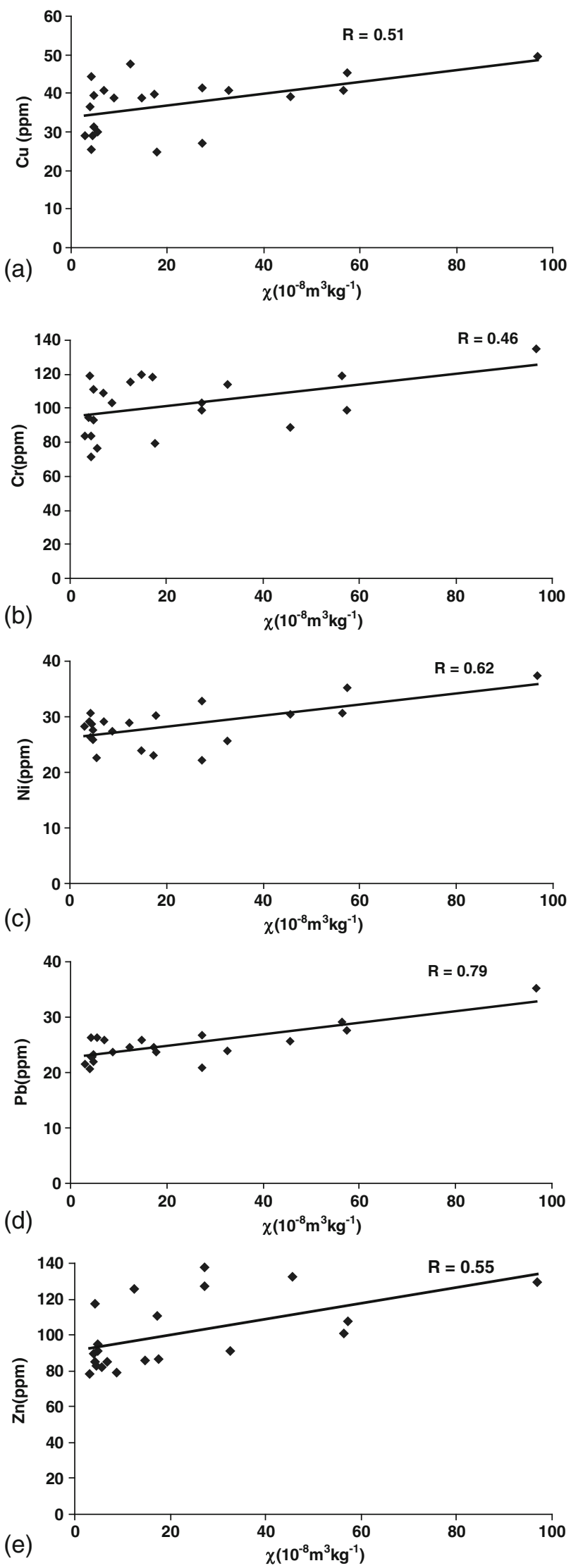

Figure 12. (a-e) Plot of $\mathrm{Cu}, \mathrm{Cr}, \mathrm{Ni}, \mathrm{Pb}$ and $\mathrm{Zn}$ vs. $\chi$ in Chennai coastal sediments. $\chi_{\text {ARM }} / \mathrm{SIRM}$ and SIRM $/ \chi$ ) reveal that the Chennai harbour, Cooum and Adayar rivers sediments are dominated by super-paramagnetic (SP) or single domain (SD) minerals.

\subsection{Abundant and heavy metals distribution}

The results of the abundant ( $\mathrm{Fe}, \mathrm{Al}, \mathrm{Mg})$ and heavy metals $(\mathrm{Cu}, \mathrm{Cr}, \mathrm{Ni}, \mathrm{Pb}, \mathrm{Zn}$ and $\mathrm{Mn}$ ) are shown in figures 9 and 10, respectively.

The concentration ranges of abundant elements $\mathrm{Al}, \mathrm{Fe}$, and $\mathrm{Mg}$ are $8.13-9.27 \%, 3.37-4.32 \%$, and $0.68-1.97 \%$, respectively. The concentrations of heavy metals in Chennai coastal sediments are $\mathrm{Cu}: 24.66-49.66 \mathrm{ppm}$; Cr: $71.18-134.7 \mathrm{ppm}$; Ni: 22.1-37.42 ppm; Pb: 20.74-35.22 ppm, Zn: 78.38$137.46 \mathrm{ppm}$ and $\mathrm{Mn}: 254.94-426.34 \mathrm{ppm}$, respectively. The pollution load index of Chennai coastal sediments is shown in figure 11.

The PLI gives an assessment of the overall toxicity status for a sample, and it is the result of the contribution of five heavy metals $(\mathrm{Cu}, \mathrm{Cr}, \mathrm{Ni}, \mathrm{Pb}$ and $\mathrm{Zn}$ ). The enrichment of heavy metals in sample E1, E2, CH7, C11, C12 and A16 is mainly due to anthropogenic activities such as, harbour activities, Cooum and Adayar rivers input, excess input of industrial effluent in these regions.

\subsection{Relationship between magnetic properties and heavy metals}

In order to identify the relationship between the magnetic susceptibility and heavy metal concentrations, the correlation analysis was carried out. The concentrations of the five heavy metals $(\mathrm{Cu}, \mathrm{Cr}$, $\mathrm{Ni}, \mathrm{Pb}$, and $\mathrm{Zn}$ ) are plotted against the magnetic susceptibility in figure $12(\mathrm{a}, \mathrm{b}, \mathrm{c}, \mathrm{d}$ and e) respectively, where the correlation coefficients between the heavy metal concentrations and magnetic susceptibility are also given.

In general, all heavy metals show moderate correlation with magnetic susceptibility. The highest correlation coefficient $(R=0.79)$ is obtained between the magnetic susceptibility and $\mathrm{Pb}$. Correlations between the magnetic susceptibility and the concentration of other heavy metals are as follows: $\mathrm{Ni}(R=0.62), \mathrm{Zn}(R=0.55), \mathrm{Cu}(R=$ $0.51)$, and $\operatorname{Cr}(R=0.46)$. The correlations between magnetic concentration parameters $\left(\chi, \chi_{\mathrm{ARM}}\right.$ and SIRM) and pollution load index (PLI) were also obtained for the Chennai coastal sediment samples and are shown in figure $13(\mathrm{a}, \mathrm{b}$ and $\mathrm{c})$ respectively.

The significant positive correlations were obtained between magnetic concentration parameters $(\chi$, $\chi_{\mathrm{ARM}}$ and SIRM) with PLI. The significant 

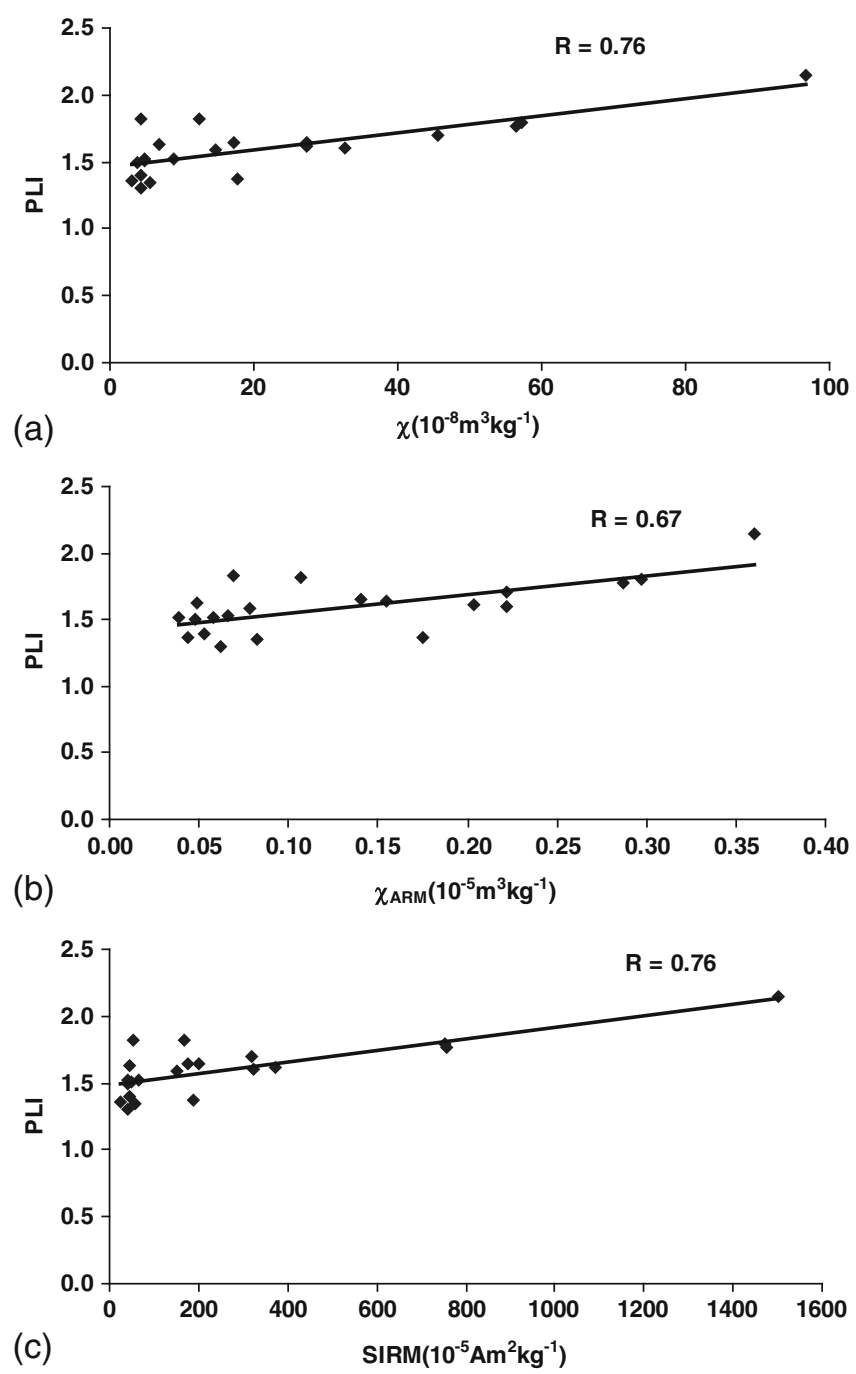

Figure 13. (a-c) Plot of $\chi, \chi_{\mathrm{ARM}}$ and SIRM vs. PLI in Chennai coastal sediments.

correlations suggest that magnetic measurements can be used as a rapid and inexpensive method for proxy indicator and screening/monitoring of heavy metal pollution in sediments due to anthropogenic activities such as discharge and disposal of treated/untreated sewage and industrial wastes, harbor and shipping activities.

Multivariate statistical technique is more apt to account for complicated links between pollutants and magnetic parameters (Bityukova et al 1999). R-mode factor analysis with varimax-normalized rotation by means of the principal components extraction method was attempted to identify common sedimentological and geochemical characteristic of the original data. Factor analysis was conducted on the magnetic parameters and heavy metal concentrations of the sediment samples, which help to discuss the magnetic parameters and their links to heavy metals for a better understanding of distribution and vertical migration of pollutants in sediment profile.

The grouping of analyzed parameters are done by using varimax rotation factor analysis and two factors are presented as factor 1 (F1), and factor 2 (F2) which are illustrated in figure 14, describing $64.86 \%$ of cumulative percentage for the Chennai coastal sediments. Factor 1 accounts for $52.5 \%$ of variance with an Eigen value of 9.98. The second factor (F2) accounts for $12.36 \%$ of variance with an Eigen value of 2.35. F1 showed high positive factor loading $(0.63-0.96)$ of most of the variables $\left(\chi, \chi_{\mathrm{ARM}}, \mathrm{SIRM}\right.$, Soft IRM, Hard IRM, Fe, $\mathrm{Al}, \mathrm{Cu}, \mathrm{Cr}, \mathrm{Ni}, \mathrm{Pb}$ and $\mathrm{Zn}$ ). F1 also has high negative factor loading $(-0.65$ to -0.84$)$ with $\chi_{\mathrm{fd}} \%$, $\chi_{\text {ARM }} / \chi$ and $\chi_{\text {ARM }} /$ SIRM. F2 showed high positive factor loadings with two variables ( $\mathrm{Fe}$ and $\mathrm{Ni}$ ) and negative loading with Mg. As indicated by the factor analysis, the magnetic concentration parameters $\left(\chi, \chi_{\mathrm{ARM}}\right.$ and SIRM) covary with heavy metal concentrations, suggesting that the input of magnetic minerals and heavy metals in the Chennai coastal sediments are derived from the same anthropogenic sources such as discharge and

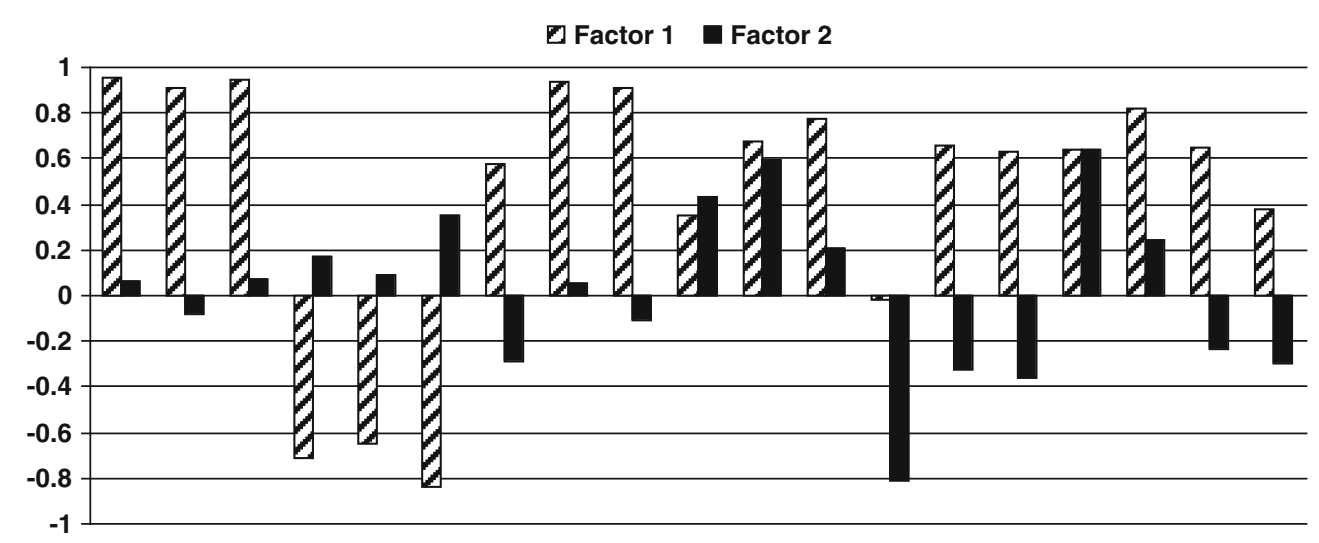

Figure 14. Results of factor analysis (R-mode) showing the association of the two primary factors for Chennai coastal sediments. 
disposal of treated/untreated sewage and industrial wastes, harbor and shipping activities.

\section{Conclusion}

The Chennai coastal sediment samples are dominated by ferrimagnetic minerals corresponding to magnetite-like minerals. The percentage of frequency dependent magnetic susceptibility reflects the presence of super-paramagnetic or single domain magnetic minerals in Chennai harbour, Cooum and Adayar rivers sediments. High pollution load index in samples E1, E2, CH7, C11, C12 and A16 is mainly due to anthropogenic activities such as, harbour activities, Cooum and Adayar rivers input, excess input of industrial effluent in these regions. Strong correlations obtained between pollution load index (PLI) and concentration dependent parameters $\left(\chi, \chi_{\mathrm{ARM}}\right.$ and SIRM) for the polluted samples with magnetic susceptibility excess of $50 \times 10^{-8} \mathrm{~m}^{3} \mathrm{~kg}^{-1}$. Factor analysis shows that the magnetic concentration dependent parameters $\left(\chi, \chi_{\mathrm{ARM}}\right.$ and SIRM) covary with the heavy metals, suggesting that the input of magnetic minerals and heavy metal concentrations in the Chennai coastal sediments are derived from the same sources. Significant correlations between heavy metals and magnetic susceptibility point out the potential of magnetic screening/monitoring for simple and rapid proxy indicator of heavy metal pollution in marine sediments.

\section{Acknowledgements}

This study has been carried out in the framework of the MoES Research Project (Project No. MoES/11-MRDF/1/13/P/07), New Delhi. Authors are thankful to Prof. T Balasubramanaian, Director, Centre of Advanced Study in Marine Biology, Faculty of Marine Sciences, Annamalai University, Parangipettai, for providing all the facilities. The authors wish to thank the Director, Indian Institute of Geomagnetism, Mumbai, for permitting magnetic measurements. We also thank the crew of RV Sagar Paschimi for their help during the cruise.

\section{References}

Abrahim G M S and Parker R J 2008 Assessment of heavy metal enrichment factors and the degree of contamination in marine sediments from Tamaki Estuary, Auckland, New Zealand; Environ. Monit. Assess. 136 227-238.

Alagarsamy R 2009 Environmental magnetism and application in the continental shelf sediments of India; Mar. Environ. Res. 68 49-58.
Angulo E 1996 The Tomlinson pollution load index applied to heavy metal 'Mussel-Watch' data: A useful index to assess coastal pollution; Sci. Total Environ. 187 19-56.

Bityukova L, Scholger R and Birke M 1999 Magnetic susceptibility as indicator of environmental pollution of soils in Tallinn; Phys. Chem. Earth 24 829-835.

Canbay M, Aydin A and Kurtulus C 2010 Magnetic susceptibility and heavy-metal contamination in topsoils along the Izmit Gulf coastal area and IZAYTAS (Turkey); J. Appl. Geophys. 70 46-57.

Chan L S, Ng S L, Davis A M, Yim W W S and Yeung C H 2001 Magnetic properties and heavy metal contents of contaminated seabed sediments of Penny's Bay, Hong Kong; Mar. Pollut. Bull. 42 569-583.

Chan L S, Yeung C H, Yim W W S and Or O L 1998 Correlation between magnetic susceptibility and distribution of heavy metals in contaminated sea-floor sediments of Hong Kong harbour; Environ. Geol. 36 1-2.

Dearing J A 1994 Environmental magnetic susceptibility: Using the Bartington MS2 system; Chi Publishing, Kenilworth, U.K.

Flanders P J 1994 Collection, measurement, and analysis of airborne magnetic particulates from pollution in the environment; J. Appl. Phys. 75 5931-5936.

Hay K L, Dearing J A, Baban S M J and Loveland P 1997 A preliminary attempt to identify atmosphericallyderived pollution particles in English topsoils from magnetic susceptibility measurements; Phys. Chem. Earth 22 $207-210$.

Higgitt S R, Oldfield F and Appleby P G 1991 The record of land use change and soil erosion in the late Holocene sediment of the Petit Lac d'Annecy, eastern France; The Holocene 1 14-28.

Horng C-S, Huh C-A, Chen K-H, Huang P-R, Hsiung K-H and Lin H-L 2009 Air pollution history elucidated from anthropogenic spherules and their magnetic signatures in marine sediments offshore of southwestern Taiwan; J. Mar. Syst. 76 468-478.

Karlin R, Lyle M and Ross Heath G 1987 Authigenic magnetite formation in suboxic marine sediments; Nature $\mathbf{3 2 6}$ 490-493.

Lovley D R, Stolz J F, Nord J G L and Phillips E J P 1987 Anaerobic production of magnetite by a dissimilatory iron reducing microorganism; Nature 330 252-255.

Maher B A 1988 Magnetic properties of some synthetic submicron magnetites; Geophys. J. 94 83-96.

Maher B A 1998 Magnetic properties of modern soils and Quaternary loessic paleosols: Paleoclimatic implications; Palaeogeogr. Palaeoclimatol. Palaeoecol. 137 25-54.

Maher B A and Taylor R M 1988 Formation of ultrafine grained magnetite in soils; Nature 336 368-370.

Maher B A and Thompson R 1999 Quaternary climates, environments and magnetism; Cambridge University Press, p. 383.

Maher B A, Thompson R and Hounslow M W 1999 Introduction; In: Quaternary Climate, Environments and Magnetism (eds) Maher B A and Thompson R (Cambridge: Cambridge University Press), pp. 1-48.

Matzka J and Maher B A 1999 Magnetic biomonitoring of roadside tree leaves: Identification of spatial and temporal variations in vehicle-derived particulates; Atmos. Environ. 33 4565-4569.

Oldfield F and Richardson N 1990 Lake sediment magnetism and atmospheric deposition; Philos. Trans. Roy. Soc. London B $\mathbf{3 2 7} 325-330$.

Peters C and Dekkers M J 2003 Selected room temperature magnetic parameters as a function of mineralogy, concentration and grain size; Phys. Chem. Earth 28 659-667. 
Taylor S R and McLennan S M 1995 The geochemical evolution of the continental crust; Rev. Geophys. 33 241-265.

Thompson R and Oldfield F 1986 Environmental Magnetism, Allen and Unwin, London.

Venkatachalapathy R, Veerasingam S, Basavaiah $\mathrm{N}$ and Ramkumar T 2010 Comparison between petroleum hydrocarbon concentrations and magnetic properties in
Chennai coastal sediments, Bay of Bengal, India; Mar. Petrol. Geol. 27 1927-1935.

Walden J, Smith J P and Oldfield F 1999 Environmental magnetism: A practical guide, Quaternary Research Association Technical Guide, vol. 6, 243p.

Zhou L P, Oldfield F, Wintle A G, Robinson S G and Wang J T 1990 Partly pedogenic origin of magnetic variations in Chinese loess; Nature 346 737-739.

MS received 26 June 2010; revised 13 March 2011; accepted 5 May 2011 